\title{
Thermal decomposition of ammonium hexachloroosmate
}

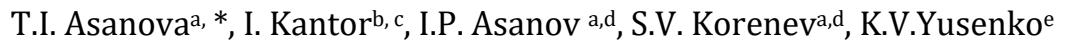

Structural changes of $\left(\mathrm{NH}_{4}\right)_{2}\left[\mathrm{OsCl}_{6}\right]$ happening during thermal decomposition in a reduction atmosphere have been studied in situ using combined energy-dispersive $\mathrm{x}$-ray absorption spectroscopy (ED-XAFS) and powder X-ray diffraction (PXRD). According to PXRD, $\left(\mathrm{NH}_{4}\right)_{2}\left[\mathrm{OsCl}_{6}\right]$ transforms directly to metallic Os without a formation of any crystalline intermediates but through a plateau where no any reactions occur. XANES and EXAFS data by means of Multivariate Curve Resolution (MCR) analysis shows that the thermal decomposition goes with a formation of amorphous intermediate $\left\{\mathrm{OsCl}_{4}\right\}_{\mathrm{x}}$ with possible polymeric structure. Being revealed for the first time the intermediate was subjected to determination of local atomic structure around osmium. The thermal decomposition of hexachloroosmate is much more complex and occurs within minimum two-step process, which has never been observed before.

\section{Introduction}

Ammonium hexachlorometalates $\left(\mathbf{N H}_{4}\right)_{2}\left[\mathbf{M C l}_{6}\right](\mathrm{M}=\mathrm{Pt}, \mathrm{Pd}, \mathrm{Ir}, \mathrm{Os}, \mathrm{Re})$ with a cubic crystal structure of $\mathrm{F} m \overline{3} m$ space group are well known complex compounds since 1817.1, $2\left(\mathbf{N H}_{\mathbf{4}}\right)_{2}\left[\mathbf{M C l}_{\mathbf{6}}\right]$ can be easily synthetized in water solutions and traditionally used as precursors for many industrial scale processes such as preparation active pharmaceutical ingredients, heterogeneous and electrocatalysts as well as various nanocomposites materials. ${ }^{3-5}$ While the thermal reactivity of hexachlorometalates plays important role in understanding of stability and transformations in solid state, their thermal decomposition in solid state was studied since the first thermal analysis techniques were developed. ${ }^{2}$ Recent developments in precise in situ in house and synchrotronbased techniques including time resolved X-ray diffraction and fast X-ray absorption spectroscopy where each data point can be collected within seconds ${ }^{6,7}$ and even microseconds ${ }^{8-10}$ make possible the re-evaluation of our knowledge about many classical reactions in solution and solid state.

Thermal decomposition of ammonium hexachlorometalates has been mainly investigated in inert atmosphere. Previous TG (thermogravimetric) data collected in inert atmosphere for $\left(\mathrm{NH}_{4}\right)_{2}\left[\mathbf{M C l}_{6}\right]$ salts with Ir, Re and Os did not suggest a formation of any intermediates in the following stoichiometric reaction: 11

$$
3\left(\mathrm{NH}_{4}\right)_{2}\left[\mathbf{M C l}_{6}\right] \rightarrow 3 \mathrm{M}+2 \mathrm{~N}_{2}+16 \mathrm{HCl}+2 \mathrm{NH}_{4} \mathrm{Cl}
$$

Thermal decomposition of Pt and Pd $\left(\mathbf{N H}_{4}\right)_{2}\left[\mathbf{M C l}_{6}\right]$ salts seems to be particularly complicated. In situ XAFS experiments with $\left(\mathrm{NH}_{4}\right)_{2}\left[\mathrm{PdCl}_{6}\right]$ at $\mathrm{Cl} \mathrm{K}$ - and $\mathrm{Pd} / \mathrm{Rh} \mathrm{L}_{3}$-edges ${ }^{12}$ suggested a formation of several intermediates such as $\mathrm{Pd}\left(\mathrm{NH}_{3}\right) \mathrm{Cl}_{5}$, trans- $\mathrm{Pd}\left(\mathrm{NH}_{3}\right)_{2} \mathrm{Cl}_{2}$ or $\left(\mathrm{NH}_{4}\right)_{2}\left[\mathrm{PdCl}_{4}\right]$. Similar experiment with $\left(\mathrm{NH}_{4}\right)_{2}\left[\mathrm{PtCl}_{6}\right]^{13}$ revealed a fingerprint of cis- $\mathrm{Pt}\left(\mathrm{NH}_{3}\right)_{2} \mathrm{Cl}_{2}$, however, supposing some other platinum amine complexes as intermediates. Direct evidence of cis- $\mathrm{Pt}\left(\mathrm{NH}_{3}\right)_{2} \mathrm{Cl}_{2}$, formation has been recently obtained using microsecond time-resolved energy dispersive EXAFS ${ }^{9}$ proving the two-step thermal reaction process:

$$
\left(\mathrm{NH}_{4}\right)_{2}\left[\mathrm{PtCl}_{6}\right] \rightarrow \text { cis- } \mathrm{Pt}\left(\mathrm{NH}_{3}\right)_{2} \mathrm{Cl}_{2} \rightarrow \mathrm{Pt}
$$

Such findings suggest us that visually simple reaction being investigated by more powerful techniques with more precision may open many unsolved problems and show high level of complexity depending on the level of our knowledge. An application of in situ techniques with ultrafast time resolution may give important information about the process including kinetic data.

In the present study we report in situ energy-dispersive XAFS and fast time-resolved PXRD investigation of the thermal decomposition process of ammonium hexachloroosmate, $\left(\mathrm{NH}_{4}\right)_{2}\left[\mathrm{OsCl}_{6}\right]$. Each of these methods is used for studying solid-state chemical reactions accompanied by structural and compositional transformations as well as a number of phases/species. ${ }^{14-16}$ However, the combination of the methods has been shown to be more powerful because one provides changes in 
both short- and long-range atomic order during chemical transformation. ${ }^{17-20}$ Hydrogen has been applied as reducing agent to initiate the following stoichiometric reaction:

$$
\left(\mathrm{NH}_{4}\right)_{2}\left[\mathrm{OsCl}_{6}\right]+2 \mathrm{H}_{2} \rightarrow \mathrm{Os}+2 \mathrm{NH}_{4} \mathrm{Cl}+4 \mathrm{HCl}(3)
$$

\section{Experimental}

Polycrystalline $\left(\mathrm{NH}_{4}\right)_{2}\left[\mathrm{OsCl}_{6}\right]$ has been obtained from abcr GmbH \& Co. KG (Germany).

In situ XAFS experiment was performed on ID24 beamline at the European Synchrotron Radiation Facility. More information about the beamline layout can be found elsewhere. ${ }^{21}$ For XAFS experiments, a mixture of polycrystalline $\left(\mathrm{NH}_{4}\right)_{2}\left[\mathrm{OsCl}_{6}\right]$ and $\mathrm{BN}(1: 10$ volume ratio) was pressed in a pellet. Os L3-edge XAFS spectra were collected in transmission mode upon heating $(6 \mathrm{~K} / \mathrm{min})$ in a reduction atmosphere (2 vol.\% $\mathrm{H}_{2} / \mathrm{He}$ ). FReLoN (Fast-Readout Low-Noise) high-frame-rate detector was used for fast continuous collection of X-ray absorption spectra ${ }^{22}$ every minute. A Pt foil was used as a reference for pixel-to-energy calibration. X-ray beam was re-focused vertically with the silicon mirror, so that the final X-ray spot size on the sample was $15(\mathrm{v}) \times 7(\mathrm{~h}) \mu \mathrm{m}^{2}$, FWHM. EXAFS data was treated by IFEFFIT software.23, 24

Multivariate Curve Resolution - Alternative Least Squares (MCR-ALS) analysis of XANES and EXAFS $(\chi(\mathrm{k}))$ was applied for a selection of the contributions of the different species to experimental spectra. ${ }^{25,26}$ In the framework of the MRS-ALS method, the experimental data matrix D is represented as a bilinear model of the pure components

$$
D=C S^{T}+E
$$

The data matrix D encloses measured intensities in columns and measured samples (in our case, different temperatures) in rows. $\mathrm{C}$ is a matrix of concentrations showing contributions of the pure components into the measured spectra. ST is a transpose of the matrix of the pure component spectra, and $\mathrm{E}$ is a matrix of residuals representing the unexplained variance of data. For the selfconsistent analysis of the same samples by XANES and EXAFS methods, we used a multi-set analysis using the augmented row-wise data matrix. In this case, we analysed the following equation

$\left[D_{X A N E S} D_{E X A F S}\right]=\left[C^{i}\right]\left[S_{X A N E S}^{i} S_{E X A F S}^{i}\right]+\left[E_{X A N E S}^{i} E_{E X A F S}^{i}\right]$ (5)

Here, the data matrix $D$, the matrix of the component spectra $S$ and matrix of residuals $E$ enclose two sub-blocks describing XANES and EXAFS, correspondingly. The number of components is determined based on the results of the principal component analysis. The initial estimations were selected by recognizing that in the initial and final stages of the thermal process there are only the spectra of the complex salt or the metal, correspondingly. The preliminary estimations were obtained using XANES data only and consequently applied for the total simultaneous multi-set analysis of XANES and EXAFS data. In the analysis procedure, we used the non-negativity constraints for concentration and XANES intensities using the fnnls algorithm, ${ }^{26}$ the unimodality constraint for concentration using the average option with a $10 \%$ of tolerance for all the species, and the condition of invariability of osmium with the total closure constant equal to 1 for all the components. The quality of fitting was estimated using the following parameters: percent of variance explained R2 and lack of fit (\%). ${ }^{26}$ At the optimum, the lack of the fit of experimental data matrix $^{25}$ was $3.8 \%$, percent of variance explained was $99.86 \%$. Details of the MRS-ALS can be also found somewhere. ${ }^{27}$

In situ PXRD experiments were performed at the Swiss-Norwegian Beam Lines (BM01A), ESRF. Sample for PXRD experiment was placed in $0.5 \mathrm{~mm}$ fused quartz mark tube (Hilgenberg $\mathrm{GmbH}$, Germany) and heated in a 2 vol.\% $\mathrm{H}_{2} / \mathrm{He}$ flow (0.1-0.5 ml/min) with a hot air stream from room temperature to $1000 \mathrm{~K}$ with a ramp rate of $10 \mathrm{~K} / \mathrm{min}$. Temperature has been calibrated using thermal expansion of the cell parameters for silver powder as an external standard. The wavelength $(\lambda=0.68894 \AA)$ and sample-to-detector distance have been calibrated using a LaB 6 powder (NIST SRM 660c) as an external standard. Data were collected every $20 \mathrm{~s}$ (3 K per minute in temperature scale) using a PILATUS2M 2D flat detector. The data were converted and diffracted intensities integrated using the SNBL software toolbox. ${ }^{28}$ Temperature dependent PXRD patterns were plotted and analysed using Powder3D software. ${ }^{29}$ Phase composition was verified using the PDF database. ${ }^{30}$ Data were fitted using parametric sequential refinements realised in the TOPAS software. ${ }^{31}$ The best fits were obtained using Gaussian peak profile function. Only two crystalline phases, namely $\left(\mathrm{NH}_{4}\right)_{2}\left[\mathrm{OsCl}_{6}\right]$ and hcp-Os, were detected in the whole temperature range. Profile parameters for the Gaussian function, cell parameters, and phase fractions were refined simultaneously for both phases. 

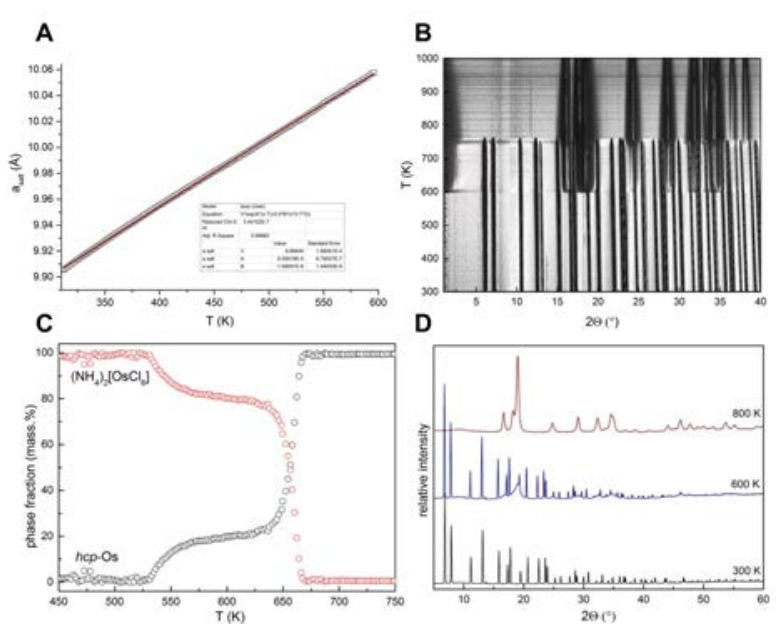

Figure 1. (a)Temperature dependence of cubic cell parameters for $\left(\mathrm{NH}_{4}\right)_{2}\left[\mathrm{OsCl}_{6}\right]$ upon heating (solid line corresponds to fitted curves according to Equation (6)); (b) temperature dependence of PXRD patterns (2D-film top view) upon heating the salt $\left(\mathrm{NH}_{4}\right)_{2}\left[\mathrm{OsCl}_{6}\right]$; (c) Temperature dependence of weight fractions for $\left(\mathrm{NH}_{4}\right) 2\left[\mathrm{OsCl}_{6}\right]$ and hcp-Os upon heating refined from PXRD data; (d) selected PXRD patterns obtained at 300, 600 and $800 \mathrm{~K}$. All data were collected in 2 vol. $\% \mathrm{H}_{2} / \mathrm{He}$ flow $(\lambda=0.68894 \AA)$.

\section{Result and discussion}

\subsection{X-ray diffraction}

Our experiments at low and high temperatures suggest that $\left(\mathrm{NH}_{4}\right)_{2}\left[\mathrm{OsCl}_{6}\right]$ does not show any phase transitions below decomposition temperature. Low temperature cooling down to $4 \mathrm{~K}$ does not induce any phase changes either. Temperature expansion of cell parameters for $\left(\mathrm{NH}_{4}\right)_{2}$ [OsCl 6 between 293 and $500 \mathrm{~K}$ in the form $\alpha(T)=\alpha_{\mathrm{o}}+\alpha_{1} T$ can be fitted using following exponential approximation:

$$
a(T)=a_{\mathrm{o}} \exp \left[\int_{T_{0}}^{T} \alpha(T) d T\right]
$$

where $a_{0}$ is cell parameter at reference temperature $\left(\mathrm{T}_{0}=293 \mathrm{~K}\right) \cdot{ }^{32}$ Corresponding thermal expansion parameters were determined as following: $a_{0}=9.8662(2) \AA ̊\left(T_{0}=293 \mathrm{~K}\right) ; \alpha_{0}=6.06(7) \cdot 10^{-}$ $5 \mathrm{~K}^{-1}$ and $\alpha_{1}=-1.7(1) \cdot 10^{-9} \mathrm{~K}^{-2}$ (Fig. 1a).

According to in situ PXRD data, visible changes in diffraction patterns can be detected only above $525 \mathrm{~K}$ (Fig. 1). TG data show a visible mass loss above $550 \mathrm{~K}$ (see Supplementary Fig. 1), which is in agreement with PXRD results. In the whole temperature interval, only starting $\left(\mathrm{NH}_{4}\right)_{2}\left[\mathrm{OsCl}_{6}\right]$ and hcp-Os phases can be detected. No visible crystalline intermediates were detected in PXRD profiles. Relative phase fractions characteristic for both phases have been estimated using Rietveld refinement of each diffraction profile. It should be noted that in the intermediate temperature range (525-640 K) diffraction lines characteristic for hcp-Os are relatively broad which can be associated with a formation of small metallic particles or other amorphous intermediates. The quality of the peak fit and final refinement of the data in the «intermediate» temperature range is degraded because of the increased peak weights due to the presence of poorly crystallized nanoparticles.

The temperature evolution of estimated phase fractions of $\left(\mathrm{NH}_{4}\right)_{2}\left[\mathrm{OsCl}_{6}\right]$ and hcp-Os visually shows a "quasi" two-step process of thermal decomposition. First stage (525-640 K) can be also associated with a formation of amorphous intermediate

and relatively small hcp-Os nanoparticles barely seen in the diffraction profiles. Due to the low intensity of relatively broad diffraction lines characteristic for hcp-Os on the first stages of thermal decomposition, information obtained by PXRD on early decomposition stages is strictly limited.

Above $700 \mathrm{~K}$, only $h c p$-Os phase can be detected. Cell parameters refined can be used for the calculation of thermal expansion coefficients for pure Os metal. Corresponding volumetric thermal 


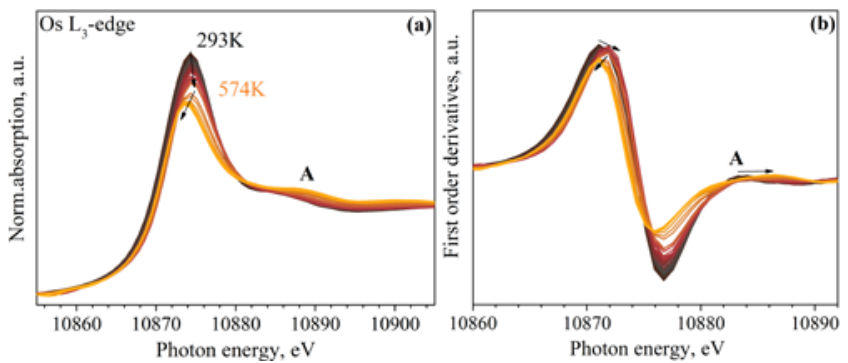

Figure 2. (a) In situ XANES spectra measured in temperature range of 298-688 K and (b) their first order derivatives. expansion coefficients were fitted following analytical dependence of atomic volume on the temperature. ${ }^{32}$ Volumetric thermal expansion coefficient in the form $\alpha(T)=\alpha_{\mathrm{o}}+\alpha_{1} T$ was obtained by fitting the corresponding dataset to

$$
\frac{V(T)}{Z}=\frac{V\left(T_{0}\right)}{Z} \exp \left[\int_{T_{0}}^{T} \alpha(T) d T\right]
$$

where $\mathrm{V}\left(\mathrm{T}_{0}\right) / \mathrm{Z}$ is atomic volume at reference temperature $(293 \mathrm{~K})$. The resulting calculated values for $\alpha_{0}$ and $\alpha_{1}$ together with thermal expansion coefficients at $273 \mathrm{~K}$ are summarized in Table 1 . Thermal expansion of pure hcp-Os has been investigated previously in 1932 and 1976.

Arblaster in his recent review ${ }^{33}$ summarized that data for pure Os obtained previously cannot be considered as final due to limited number of experimental data points reported in the literature and low agreement between authors.

\subsection{X-ray absorption spectroscopy}

XANES data can provide much more detailed information about latent intermediates of the decomposition process. XANES spectra at the Os $\mathrm{L}_{3}$-edge measured during a thermal decomposition of $\left(\mathrm{NH}_{4}\right)_{2}\left[\mathrm{OsCl}_{6}\right]$ are presented in Fig. 2a. As temperature increases up to $574 \mathrm{~K}$ a white line originated from electron transition $2 \mathrm{p}$-unoccupied level and therefore reflected density of unoccupied states shifts to high-energy range and its intensity lowers. The white line shift is about $0.5 \mathrm{eV}$ as it clearly shows temperature behaviour of first order derivative (Figure 2b). A special attention deserves a post-edge peak $\mathbf{A}$ originated from a coupling of the final photoelectron state with the localized atomic $\mathrm{Cl} 3 \mathrm{~d}$-states in the structure mediated by multiple scattering. ${ }^{34}$ As seen in Fig. 2 and Supplementary Fig. 2, the peak A modifies its shape, intensity and position under temperature that could indicate continuous changes in the first coordination sphere of osmium. The integrated white line area, determined as a difference between the white line area of spectrum measured at temperatures and that of $\left(\mathrm{NH}_{4}\right)_{2}\left[\mathrm{OsCl}_{6}\right]$, decreases in the temperature ranges of 295440 and 440-525 K demonstrating a different slope in decreasing of a density of unoccupied states at Os (Fig.3). This effect accomplishes the positive shift of the absorption edge. A change of electronic structure can be responsible for an increase of Os charge following the decomposition of $\left(\mathrm{NH}_{4}\right)_{2}\left[\mathrm{OsCl}_{6}\right]$ with a formation of low-coordinated intermediates. Taking into account a nature of the peak $\mathbf{A}$, the change in its area should correlate with Os-Cl coordination number in the first Os coordination shell (Supplementary Fig. 2a). However, a difference in specific area characteristic for peak $\mathbf{A}$ for 4 and 6 coordinated Os is not clear. At the same time, osmium halogenides are mainly hexacoordinated independently on the oxidation state. ${ }^{35}$

Fourier transformed $\mathrm{k}^{2} \chi(\mathrm{k})$ EXAFS functions in the whole temperature range presented in Fig.4 demonstrates a temperature-induced behaviour of pair distribution function of $\left(\mathrm{NH}_{4}\right)_{2}\left[\mathrm{OsCl}_{6}\right]$ (here $r$ is an interatomic distance without phase-

Table 1. Volume thermal expansion parameters for hcp-Os on heating

\begin{tabular}{|c|c|c|c|c|c|}
\hline Composition & $\begin{array}{c}\text { V0/Z, } \AA^{3} \text { atom }^{-1} \\
\mathrm{~T}=293.15 \mathrm{~K}\end{array}$ & $\alpha_{0} \bigcirc 10^{5}, \mathrm{~K}-1$ & $\alpha_{1} \bigcirc 10^{8}, \mathrm{~K}^{-2}$ & $\begin{array}{c}\text { Thermal expansion } \\
\text { coefficient } \\
\text { at } \mathrm{T}=293 \mathrm{~K}, \alpha(293) 10^{5}, \mathrm{~K}^{-1}\end{array}$ & Ref. \\
\hline hcp-Os & $13.9843(2)$ & $1.35(1)$ & $0.47(2)$ & 1.36 & 33 \\
\hline hco-Os (heating) & $13.988(2)$ & $2.73(9)$ & -1.1(1) & $2.7(5)$ & present \\
\hline
\end{tabular}


shift correction and therefore $r$ is lower than the real interatomic distance $R$ ). A prominent peak at 1.9 $\AA$ in the Fourier transformed $\mathrm{k}^{2} \chi(\mathrm{k})$ EXAFS-functions corresponds to the first coordination shell consisting of six chlorine atoms. Monotonic decrease in amplitude and width of the peak is observed between 320 and $532 \mathrm{~K}$ and associated with a thermal disorder and decreasing a coordination number. Then, abrupt decrease in the FT is accompanied by a shift the main Os-Cl peak to lower
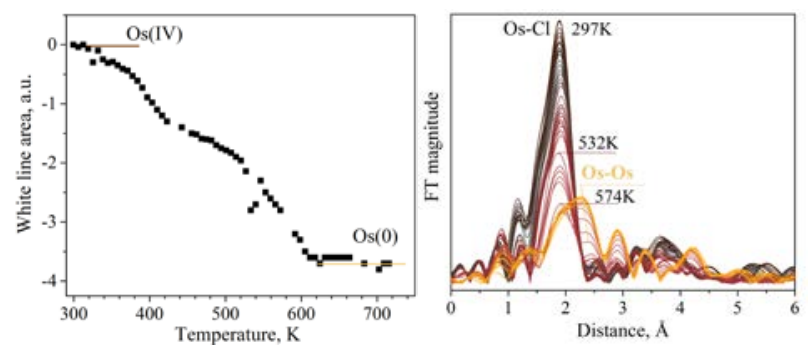

Figure 3. (left) Difference in the white line area of XANES spectrum measured at temperature and that of $\left(\mathrm{NH}_{4}\right)_{2}\left[\mathrm{OsCl}_{6}\right]$.

Figure 4. (right) Fourier transformed $\mathrm{k}^{2}$-weighted EXAFS at Os L3-edge measured during thermal decomposition of $\left(\mathrm{NH}_{4}\right)_{2}\left[\mathrm{OsCl}_{6}\right]$. distance. Above $574 \mathrm{~K}$, a longdistance shoulder appears at $2.4 \AA$ corresponding to Os-Os bonds as in metallic Os. With further increase in temperature, the shoulder amplitude grows to transform into wide and asymmetric peak at $2.3 \AA$.

Six chlorine atoms surrounded the absorbing Os atom at distance of $2.36 \AA$ were taken as an initial single-shell model for refinement of Os local structure. This model was applied till a contribution of Os-Os shell originated from metallic Os became a prominent. In the least-square fitting procedure varying EXAFS parameters such as interatomic distance (R), coordination number $(N)$, Debye-Waller factor $\left(\sigma^{2}\right)$ and correction of the threshold energy $\left(\Delta \mathrm{E}_{0}\right)$, the best parameters were found and presented in Fig.5. Spectroscopic factor $S_{0}^{2}$ was determined to be 0.7 for the initial complex at room temperature, when known coordination number was fixed at 6 . Then, the found value of $S_{0}^{2}$ was fixed for all other spectra. At room temperature, the Os-Cl distance was found to be 2.33(1) A that is in a good agreement with $2.36 \AA$ known from XRD. ${ }^{35}$ The interatomic distance reaches its maximum 2.36(1) $\AA$ at $500 \mathrm{~K}$. Simultaneously, osmium coordination number, N(Os-Cl), decreases monotonically up to 4 within estimation error. All the revealed changes in the local structure of Os above $500 \mathrm{~K}$ present a transformation of octahedrally coordinated Os to a species, where four $\mathrm{Cl}$ ions surround Os. After $525 \mathrm{~K}$, the average Os coordination number continues to decrease up to about 2 together with the bond length reaching 2.32(2) Å. Starting from $574 \mathrm{~K}$, the contribution of the metallic Os to EXAFS dominants. Above $600 \mathrm{~K}$, EXAFS spectra are well fitted by pure hcp-Os.

To obtain dynamics of $\left(\mathrm{NH}_{4}\right)_{2}\left[\mathrm{OsCl}_{6}\right]$, intermediates and product in the course of the reaction, MCR-ALC analysis has been applied to the experimental XANES and EXAFS data. As only those components containing $\mathrm{Os}$ atoms could be detected at $\mathrm{Os} \mathrm{L}_{3}$-edge and molecules such as $\mathrm{HCl}, \mathrm{NH}_{3}$ or $\mathrm{NH}_{4} \mathrm{Cl}$ were not included in analysis. The XANES and EXAFS spectra of three statistically meaningful components were selected (Fig. 6.) The other components concentrations were quite low (less than $5 \%$ ) to be included in further analysis due to their close to error bar of the signal-to-noise ratio of the data. At the optimum lack of the fit of experimental data matrix was $4 \%$, percent of variance explained was $99.83 \%$. Results of MCR-ALS analysis with an inclusion of the selected components corresponding to starting $\left(\mathrm{NH}_{4}\right)_{2}\left[\mathrm{OsCl}_{6}\right]$, one intermediate compound and metallic osmium presented in Fig. 7. The intermediate compound is formed above $320 \mathrm{~K}$ and its amount grows with temperature reaching the maximum at $525 \mathrm{~K}$. Only above $525 \mathrm{~K}$, a visible amount of metallic Os can be detected. Thus, the decrease in the white line area below $525 \mathrm{~K}$ should be associated only with a change in electronic structure of $\mathrm{Os}$ in the intermediate species. The following relatively fast
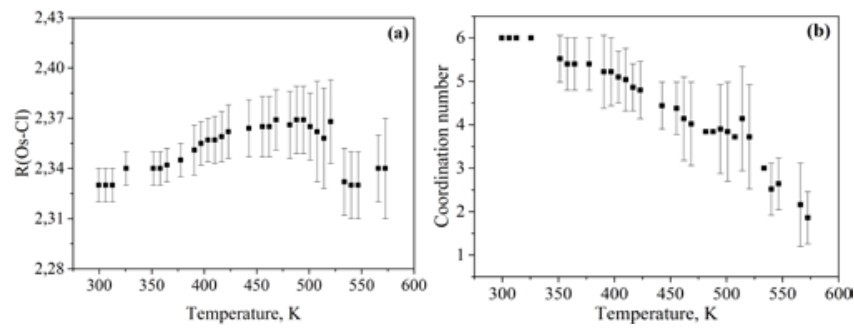

Figure 5. Variation in (a) radius and (b) coordination number of the Os-Cl shell during thermal decomposition of $\left(\mathrm{NH}_{4}\right)_{2}\left[\mathrm{OsCl}_{6}\right]$. decrease in the white line area (Fig. 3) comes from an averaging of Os oxidation state over Os(IV) and Os(0). Behaviour of the metallic and the intermediate components clearly shows two-step chemical reaction occurred under thermal decomposition.

As XAFS describes the averaged over all possible local atomic and electronic structures around the 

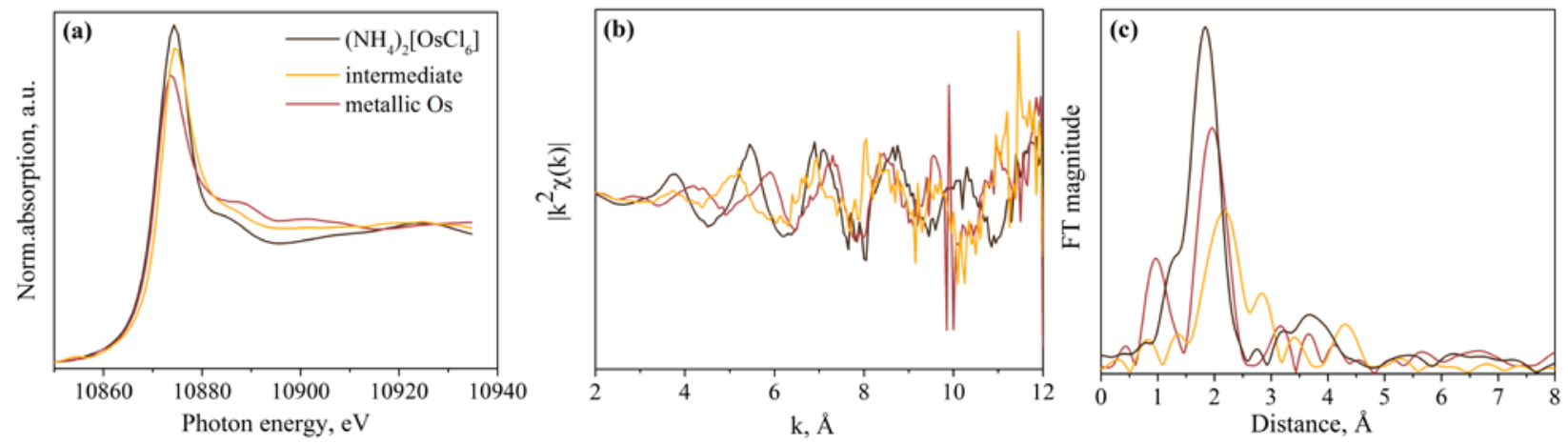

Figure 6. (a) XANES, (b) EXAFS and (c) Fourier transformed $\mathrm{k}^{2}$-weighted EXAFS of the components selected by MCR-ALS.

absorbing atom in sample, the selected XANES (Fig. 6a) and EXAFS (Fig. 6b) by MCR-ALS allow the local atomic structure of Os to disclose in the intermediate compound. The selected EXAFS-functions were Fourier transformed at similar condition as all other experimental data (Fig. 6c). Decrease in the FT magnitude of the intermediate is seen to be about $40 \%$ respect to that of the initial complex compound. FT of this intermediate compound (Figure 6c) is comparable with that presented in Fig. 4 at about $500 \mathrm{~K}$. Unfortunately, EXAFS fitting of the intermediate does not provide so precise result because of noisiness of the selected EXAFS-oscillations in the high k range (Fig. 6b). Nevertheless, the Os-Cl bond length and coordination number were estimated to be 2.37(2) $\AA$ and $4.0(4)$, respectively. (Quality of the fitting could be evaluated in Supplementary Fig. 3). Similar EXAFS parameters were observed in the temperature range of 480-525 K (Fig. 5a, b) indicating that the intermediate compound predominates at the temperatures. This agrees well with the results presented in Fig.7. As the intermediate was not detected by PXRD it could be suggested polymer nature of the intermediate.

Summarizing the analysis presented above, both techniques, in situ PXRD and XAFS, provide a direct evidence of the two-stage nature of the $\left(\mathrm{NH}_{4}\right)_{2}\left[\mathrm{OsCl}_{6}\right]$ decomposition. It is worth noted that the first stage takes place at different temperature in XANES and PXRD. The plateau in the temperature-dependent weight fractions for crystalline phases obtained by PXRD (Fig. 1c) can be directly attributed with a predominant formation of the intermediate species detected by XAFS (Fig. 7). Temperature shift between PXRD and XAFS experiments should be taken into account while both experiments were carried out at the different beamlines and different apparatuses with own specifics the temperature-induced reaction could be shifted in time and therefor in temperature. As information on amorphous intermediate is very limited in PXRD, phase ratio for crystalline phases

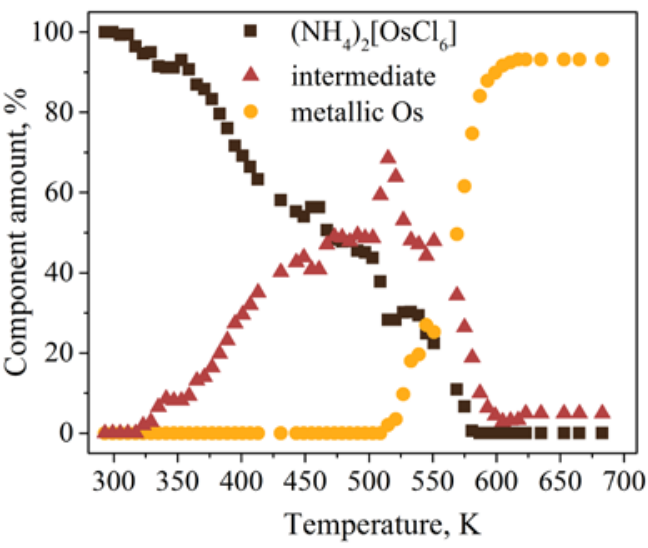

Figure 7. The temperature-induced behaviour of the $\left(\mathrm{NH}_{4}\right)_{2}\left[\mathrm{OsCl}_{6}\right]$ reactant and component formed in the course of its thermal decomposition obtained by MCR-ALS analysis. does not show complete Os balance during the reaction. Nevertheless, temperature behaviours of phase fractions detected by XRD (Fig. 1) and Os white line detected by XAFS (Fig. 3) show similar trends. Namely, both techniques show plateau $(100 \mathrm{~K}$ length) where phase fractions and Os oxidation state do not vary. Above 640 K (Fig. 1) the fraction corresponds to hcp-Os phase rapidly grows predominately at the expanse of reduction of the intermediate. Thus, the first stage concerns with formation of the Os-containing intermediate species. The intermediate becomes to be formed above $325 \mathrm{~K}$. At $525 \mathrm{~K}$, its amount reaches about $60 \%$ and at the same time the component characteristic for hcp-Os appears. 


\section{Conclusions}

Previous investigations under non-isothermal condition in a reducing atmosphere based on thermogravimetric analysis and ex situ investigations suggested the one-step decomposition of $\left(\mathrm{NH}_{4}\right)_{2}\left[\mathrm{OsCl}_{6}\right]$ according to reaction

$$
3\left(\mathrm{NH}_{4}\right)_{2}\left[\mathrm{OsCl}_{6}\right] \rightarrow 3 \mathrm{Os}+2 \mathrm{~N}_{2}+16 \mathrm{HCl}+2 \mathrm{NH}_{4} \mathrm{Cl} \text {. }
$$

Reaction being investigated using time-resolved energy-dispersive XAFS and in situ PXRD appeared to be more complex. At least one amorphous species with polymer structure and four-coordinated Os can be suggested as a main intermediate.

According to XAFS data, the thermal decomposition of $\left(\mathrm{NH}_{4}\right)_{2}\left[\mathrm{OsCl}_{6}\right]$ starts with a formation of the intermediate $\left\{\mathrm{OsCl}_{4}\right\}_{\times}$species, which enriches its maximum at $525 \mathrm{~K}$, and then the metallic Os appears. Further mass-loss can be associated with a decomposition of $\left\{\mathrm{OsCl}_{4}\right\}_{\mathrm{x}}$ intermediate:

$$
\begin{aligned}
& \left(\mathrm{NH}_{4}\right)_{2}\left[\mathrm{OsCl}_{6}\right] \rightarrow\left\{\mathrm{OsCl}_{4}\right\}_{\mathrm{x}}+\mathrm{NH}_{4} \mathrm{Cl} \\
& \left\{\mathrm{OsCl}_{4}\right\}_{\mathrm{x}} \rightarrow \mathrm{Os}
\end{aligned}
$$

First small amount of metallic Os can be detected at about $500 \mathrm{~K}$ by XAFS. Direct decomposition of $\left(\mathrm{NH}_{4}\right)_{2}\left[\mathrm{OsCl}_{6}\right]$ in $\mathrm{H}_{2}$ flow with formation of $\left\{\mathrm{OsCl}_{4}\right\}_{\mathrm{x}}$ and $\mathrm{NH}_{4} \mathrm{Cl}$ occurs on the surface of the sample as a parallel reaction. Plateau detected by XAFS and PXRD can be associated with several factors. Mainly thermally controlled growing of nano-dimensional hcp-Os particles and a blockade of reactant by $\mathrm{Os}$ and $\mathrm{NH}_{4} \mathrm{Cl}$ products should control reaction kinetic. Temperature increase leads to arise a sublimation of $\mathrm{NH}_{4} \mathrm{Cl}$ and growing Os particles.

Visually simple reaction proposed to be elementary can show complex nature being investigated using complementary powerful techniques. We suspect that thermal decomposition of other hexahalogenometallates such as $\left(\mathrm{NH}_{4}\right)_{2}\left[\mathrm{IrCl}_{6}\right]$ and $\left(\mathrm{NH}_{4}\right)_{2}\left[\mathrm{ReCl}_{6}\right]$ may show complex thermal decomposition behaviour depending on the level of our detalisation. Detailed knowledge on the mechanism for their thermal decomposition will reveals in better understanding the solid-state reactivity and stability of many coordination compounds especially species important as intermediates and pharmaceutical active ingredients.

\section{Acknowledgements}

The Swiss-Norwegian Beam Lines at the European Synchrotron Radiation Facility (ESRF) are thanked for allocation of beamtime for PXRD study as well as Dr. Dmitry Chernyshov (SNBL), Dr. Vadim Dyadkin (SNBL), Fabian L.M. Bernal and Jonas Sottmann (University of Oslo) are thanked for their support during synchrotron-based experiments. The authors are also appreciate to Pavel Plusnin (Institute of Inorganic Chemistry SB RAS, Novosibirsk, Russia) for measurement of thermal characteristics for $\left(\mathrm{NH}_{4}\right)_{2}\left[\mathrm{OsCl}_{6}\right]$ in a reducing atmosphere.

The work was supported by RFBR Grant 12-02-00354-a and 14-03-00129.

\section{Notes and references}

1 F. Wöhler, Lehrbuch der Chemie Bd.2, 951, Dresden, 1826.

2 P.Vallet, C.R. Acade.Sci., 1932, 195, 1075.

3 I. Alonso-Lemus, Y. Verde-Gomez, L. Alvarez-Contreras, Int. J. Electrochem. Sci., 2011, 6, 4176.

4 Microwave Heating as a tool for sustainable chemistry, Ed. N.E. Leadbeater, CRC Press Taylor@Francis Group, 2010, Chapter 6.

5 T.T. Cheng, E.L. Gyenge, J. Appl. Electrochem., 2008, 38, 51.

6 R. Frahm, Nucl. Instrum. Methods Phys. Res. A, 1988, 270, 578.

7 R. Frahm, Rev. Sci. Instrum., 1989, 60, 2515.

8 T. Nonaka, K. Dohmae, T. Araki, Y. Hayashi, Y. Hirose, T. Uruga, H. Yamazaki, T. Mochizuki, H. Tanida, S. Goto, Rev. Sci. Instrum., 2012, 83, 083112.

9 Q. Kong, F. Baudelet, J. Han, S. Chagnot, L. Barthe, J. Headspith, R. Goldsbrough, F.E. Picca, O. Spalla, Scientific reports, 2014, DOI: 10.1038/srep010018.

10 O. Müller, M. Nachtegaal, J. Just, D. Lützenkirchen-Hechta, R. Frahma, J. Synchrotron Rad., 2016, 23, 260.

11 G. Meyer, A. Möller, J. Less. Com. Met., 1991, 170, 327.

12 H. Rumpf,H. Modrow, J. Hormes, P. Amann, A. Möller, G. Meyer, J. Synchrotron Rad., 2001, 8, 707.

13 H. Rumpf, J. Hormes, A. Möller, G. Meyer, J. Synchrotron Rad., 1999, 6, 468.

14 P. Norby, R. Dinnebier, A.N. Fitch, Inorg. Chem., 2002, 41, 3628. 
15 S.G.Fiddy, M.A.Newton, A.J.Dent, G.Salvini, J.M.Corker, S.Turin, T.Campbell, J.Evans, Chem.Comm., $1999,851$.

16 S.Pascarelli, O. Mathon, PCCP, 2010, 12, 5535.

17 R.I. Walton, A.J. Dent, S.J. Hibble, Chem. Mater., 1998, 10, 3737.

18 P. Zalden, G. Aquilanti, C. Prestipino, O. Mathon, B. André, M. Wuttig, M.V. Coulet, J. Synchrotron Rad., 2012, 19, 806.

19 R. Kodama, Y. Terada, I. Nakai, S. Komaba, N. Kumagai, J. Electrochem. Soc., 2006, 153, A583.

20 J. M. Thomas, G. N. Greaves, Catal. Lett., 1993, 20, 337.

21 S. Pascarelli, O. Mathon, T. Mairs, I. Kantor, G. Agostini, C. Strohm, S. Pasternak, F. Perrin, G. Berruyer, P. Chappelet, C. Clavel, M.C. Dominguez, J. Synchrotron Rad., 2016, 23, 353.

22 I. Kantor, J.-C. Labiche, E. Collet, L. Siron, J.-J. Thevenin, C. Ponchut, J. Borrel, T. Mairs, C. Marini, C. Strohm, O. Mathon, S. Pascarelli, J. Synchrotron Rad., 2014, 21, 1240.

23 B. Ravel, M. Newville, J. Synchrotron Rad., 2005, 12, 537.

24 M. Newville, J. Synchrotron Rad., 2001, 8, 322.

25 J. Jaumot, R. Gargallo, A. de Juan, R. Tauler, Chemom. Intel. Lab. Sys., 2005, 76, 101.

26 J. Jaumot, A. de Juan, R. Tauler. Chemom. Intel. Lab. Sys., 2015, 140, 1.

27 T. Asanova, I. Asanov, A. Zadesentz, E. Filatov, P. Plusnin, E. Gerasimov, S. Korenev, J. Therm. Anal. Calorim., 2016, 123, 1183.

28 V. Dyadkin, SNBL Tool box. Grenoble, France: Swiss Norwegian Beamline at ESRF, 2013.

29 P. Rajiv, R. Dinnebier, M. Jansen, Materials Science Forum, 2010, 651, 97.

30 PDF-2 Release 2012 (Database), Ed. S. Kabekkodu, International Centre for Diffraction Data, Newtown Square, PA, USA, 2012.

31 TOPAS v.4.0, Bruker-AXS 5465 East Cheryl Parkway - Bruker AXS, 2009.

32 R.S. Krishnan, R. Srinavasan, S. Devanarayanan, International series on the science of the solid state, Pergamon Press, Oxford, 1979, vol.22.

33 J.W. Arblaster, Platinum Metals Rev., 2013, 57, 177.

34 A.L. Ankudinov, J.J. Rehr, S.R. Bare, Chem. Phys. Lett., 2000, 316, 495.

35 S.A. Cotton, Chemistry of precious metals. Uppingham School Rutland, UK, 1997. 